\title{
Research on the Development of Human Resources in Public Sectors Based on the Theory of "Social Man"
}

\author{
Yang Yang, Hongxun Xiang \\ School of Southwest Minzu University, Chengdu, China \\ Email: 1047127006@qq.com
}

How to cite this paper: Yang, Y., \& Xiang, H. X. (2020). Research on the Development of Human Resources in Public Sectors Based on the Theory of "Social Man". Open Journal of Social Sciences, 8, 263-270. https://doi.org/10.4236/jss.2020.812020

Received: November 25, 2020

Accepted: December 19, 2020

Published: December 22, 2020

Copyright (อ 2020 by author(s) and Scientific Research Publishing Inc. This work is licensed under the Creative Commons Attribution International License (CC BY 4.0).

http://creativecommons.org/licenses/by/4.0/

\section{(c) (i) Open Access}

\begin{abstract}
The development of human resources in the public sector is inseparable from the application of "social man" hypothesis theory. At this stage, there are still many problems in the development, management, and use of human resources in the public sector. Especially in the development and use of human resources in the public sector, there are still outstanding problems such as incomplete development and inappropriate use. Apply the "social man" hypothesis theory, scientifically develop human resources in the public sector, achieve "personal and post-fit" in the introduction and selection of talents, achieve "all-round development" in the cultivation of talents, and in the management education of talents do a good job of "equal attention to grace and power".
\end{abstract}

Keywords

Social Man, Public Sector, Human Resources, Development

\section{Introduction}

The "social man" hypothesis theory is different from the "carrot and stick" management approach advocated by the "economic man" hypothesis theory (Shao, Liu, \& Li, 2013). Instead, it pays more attention to people's social and psychological needs, emphasizing the embodiment of human value and overall progress. Aiming at the problems of incomplete development and improper use encountered in the development of human resources in the public sector, based on the "social man" hypothesis theory in Western management, scientifically carry out the introduction, selection, training and management education of talents to achieve improvement. The work enthusiasm of public sector personnel 
is to enhance the ability of public sector personnel to serve the people. At present, the Chinese government's governance model is undergoing an upgrade and transformation, an acute change from traditional management to refined governance, and social assumptions can play a positive role in improving governance; the development of human resources in the public sector in human resource management is more important. It is the starting point of governance. How to select more high-level talents is a more meaningful subject and postgraduate entrance examination. This article will focus on the social human hypothesis in the development of human resources in the public sector, explore its mode of action, and make feasible suggestions.

\section{2. "Social Man" Hypothesis Theory and Human Resources Development in Public Sector}

\subsection{The Content of "Social Man" Hypothesis Theory}

The "social man" hypothesis was first proposed in the Hawthorne experiment. Based on the Hawthorne experiment, the famous American psychologist and management scientist Mayo proposed that people are thoughtful and complex social members with different personalities and emotional expressions, not machines and animals. As a complex "social person", although money and material have a significant impact on its enthusiasm, the decisive factor is not material rewards, but the satisfaction of the psychological needs of a social person.

The main content of the hypothetical theory of "social man" is: First, people are not "economic people" who only need to be self-interested, but who need social and psychological "social people" in addition to material needs. Only when people's society and psychology are satisfied can the work efficiency be maximized; Second, advocate "people-centered" and focus on coordinating interpersonal relationships to achieve harmony; Third, attach importance to and rationally use "informal groups" to better improve team work efficiency. Because "informal groups" have unique emotions, norms and tendencies, which are conducive to improving enthusiasm; Fourth, people's work enthusiasm depends on their work attitude, and work attitude is affected by the surrounding interpersonal relationships and work environment.

\subsection{The "Social Man" Hypothesis and Its Significance to Human Resources Development}

General Secretary Xi Jinping mentioned in the report of the 19th CPC National Congress: The contradiction between people's growing need for a better life and unbalanced and insufficient development ( $\mathrm{He}, 2017)$. This is the main contradiction in Chinese society in the new era, which is different from the main contradiction in our society before the reform and opening up. "A good life" is obviously a richer and more meaningful term. It not only refers to the people's need for money and material, but also recognizes the people's desire for beauty and good things. It also contains spiritual needs. This is what the central admin- 
istrator has derived from the hypothetical theory of "social man". The conclusion fits the development of the times. Under this general tone, the training and use of public sector staff also reflects the "people-oriented" standpoint and the "humanistic care" perspective. Only by promoting the full and full development of public sector staff and using talents reasonably and appropriately can the personal ideals and goals in life be combined with national development and historical missions. This is the current general direction of the development of human resources in the public sector.

People are the first resource of human resource management. The main content of human resource development in the public sector includes four aspects: forecasting and planning, education and training, selection and use, configuration and management. In short, it corresponds to the introduction, selection, training, and management of talents in the development of human resources. Human resource development is one of the important links in the process of human resource management, and it is the most effective means for the public sector to discover talents, introduce and select talents, and cultivate talents. Young talents occupy an important position in human resources. The introduction and selection of young talents will greatly enhance the vitality of the public sector and inject fresh blood into the organization. Young talents have high academic qualifications and unlimited potential, and they are the main force to undertake work tasks. Therefore, it is said that sufficient human resource development should be carried out for this young team to give full play to the maximum effectiveness of young talents. At the same time, we must also pay attention to the cultivation of young talents' own abilities and the coordinated development and progress with units and organizations. People who are already in their jobs are also part of the human resources of the public sector, and it is also very important to develop human resources for them. In terms of practical experience, they are more mature and stable than young talents and have strong problem-solving skills.

Drawing on the theory of "social man" hypothesis, unit organizations should continue to train and manage these new and old staff. For individuals, it is necessary not only to obtain the improvement of personal ability, but also to realize the value of personal life. The ultimate guide is a successful career and a perfect life journey; As far as the organization is concerned, under the collaboration of energetic young talents and experienced veteran cadres, each task can be completed with quality and quantity, and the organizational goals can be effectively completed.

\section{Deficiencies in the Development of Human Resources in the Public Sector}

\subsection{Shortcomings in Talent Introduction and Selection}

The introduction and selection of talents is one of the important links of human resource development. However, there are still many shortcomings in this part 
of our country at this stage. In the introduction of talents, individuals often lack more options, and public organizations have not fully demonstrated the principle of "two-way choice" in the workplace. The main manifestations are: First, in the process of introduction and recruitment, individuals are usually passive, and there are few links for individuals to choose from, and the choices are very limited. For example, when Sichuan Province selects outstanding university graduates to work at the grass-roots level in 2019, the only choices available to individuals are the place of application and the general selection of position 1 and position 2. The final position in which township is based on the ranking of the graduate school decided; Second, in the process of selecting cadres, it is often difficult for staff who have no "relationships" to choose other places that are more suitable for them, and promotion is even more difficult (Liu, 2013). This traditional concept of "relationship first" still exists, leading to "people can't use their talents", and jobs can't be matched by people who are suitable for it.

\subsection{Insufficiency in the Talent Training Process}

There are still some problems in the cultivation of talents. Most of the talent training at the current stage is scattered, and there is no systematic and planned organization and training (Pan \& Yang, 2017). The unit organization did not formulate and plan long-term feasible training programs for individuals, and individual capabilities could not be effectively improved, resulting in "unable to make the best use of it", which greatly reduced the development efficiency of human resources. There is also a lack of diversity in the methods and methods of training. At this stage, the training of talents is mostly based on instilling teaching methods, and there is very little participatory training. Practice is the only criterion for testing truth. Most of the newly introduced personnel do not look down on the "elderly" who were in the unit before, thinking that their computer skills, cultural education, etc. are low; however, most "old people" also look down on the newcomers, thinking that they have high scores and low ability, do not have the ability to do things, not to mention that they have no experience. Organizations only focus on improving personal business capabilities, ignoring the need for belonging and emotional needs that individuals need to be met, lacking in shaping the sense of belonging of talents, lack of emotional communication with talents, and still in the thinking mode of "economic man".

\subsection{Shortcomings in Talent Management Education}

Talent management education is also an important part of human resource development in the public sector, but at this stage, there are still some deficiencies in this part. Leading cadres at the management level focus on command, organization, planning, and arrangement, but ignore the individual needs and development of the managed. In addition to material needs such as salary and money, personal needs also have the need for belonging and emotional communication. Of course, personal development is also one of the psychological needs. Manag- 
ers seldom emphasize the importance of team building in management education, but only pay attention to "strict management" and ignore the aspect of "kindness". Most units in the public sector are restricted by the bureaucratic structure. There are more strict hierarchical constraints between subordinates, managers and managed persons, and lack of mutual emotional communication and expressing personal opinions. Opportunities, such management methods are not conducive to the management education of talents. In the current targeted poverty alleviation work, which is the most important task, most poverty alleviation workers only pay attention to providing material subsidies to poor households, while ignoring spiritual issues. For example, in order to help targeted poverty alleviation households develop good hygiene habits, poverty alleviation workers bought tables, chairs, brooms, refrigerators, etc., but did not pay attention to communication with targeted poverty alleviation households and explained the importance of loving hygiene and caring about health.

\section{Applying the Theory of "Social Man" Hypothesis to Scientifically Develop Human Resources in the Public Sector}

\subsection{Achieve "Suitability for People and Posts" in Talent Introduction and Selection}

When organizations and units introduce and select talents, it is necessary to comprehensively consider and analyze them, and then arrange the appropriate number of talents in appropriate positions. In the process of introducing young talents, it is necessary to determine the talents according to their needs, and remember that they are not available. If the number of young talents introduced is not well controlled, too much will result in overwhelming personnel in units and departments, which will result in waste of human resources and low office efficiency in units and departments; Too little will cause a shortage of human resources in the unit and department, which will increase the burden of work tasks. In the process of selecting talents, the principle of "appropriate people and positions" should be implemented. With regard to the issues of "what the organization needs" and "what young talents want", the employing agency considers the former more. Organizations should not only ask for requirements and conditions, but should also be a listener of the demands of young talents, care about the inner needs of young talents, understand the needs of young talents development, master the characteristics of young talents, and give them organizational support. At the same time, all units and managers must also clearly realize that the virtues and abilities displayed by young talents in their work are the most direct appeals to the organization for progress and development. Special attention and great importance should be given to outstanding young talents and find the most suitable positions for them (Chen, 2017). Not only can we select the most suitable talents to the matching positions, but also effectively reduce the situation of "going through relationships" and "opening the back door", so that outstanding and energetic talents are most suitable for their aspi- 
rations. Only in this way can we provide talents with more options, and better achieve "optimal and optimal matching" and "suitability for people and positions". We have done our best to maximize the development of human resources.

\subsection{To Achieve "All-Round Development" in Personnel Training}

The hypothetical theory of "social man" advocates the all-round development of man, focusing on the improvement of personal abilities and the realization of their respective values. In the process of cultivating talents, the unit organization shall unify and formulate a long-term and effective organizational training plan. "It's only a little bit simpler on paper, and you have to do it yourself." The unit organization needs to abandon the training method that only focused on indoctrination classroom teaching, and integrate the training method of participatory training. Only in this way can we diversify the training of talents in many ways, and improve the efficiency of human resource development. Of course, unit organizations must not only diversify the training of talents and improve their personal abilities, but also train them from all aspects of "ethics, intelligence, and physical". The overall development of the individual is not only the improvement of professional knowledge, but also the improvement of ideology and morality and a healthier body. The "professionals" who are partial to one another are less and less suitable for the development of work and the needs of social development, because most positions in the public sector use comprehensive talents, and only fully-developed staff can better complete the public sector. There are still many cases of dissatisfaction between new and old staff, which are also problems that need to be solved urgently. Failure to solve them in time will affect work efficiency. Drawing on the theory of "social man" hypothesis, the unit organization strengthens the emotional exchanges between new and old staff, and guides them to look at each other's points to learn from each other's strengths. The vigorous vitality and high-level professional knowledge of the "newcomers" are the highlights, and the valuable practical experience and rich handling capabilities of the "old people" are also worth learning. Only in a collaborative atmosphere can we better develop human resources and make the best use of it. Units and organizations must use "informal groups" in a reasonable and correct manner. Sometimes this will greatly improve the efficiency of the public sector.

\subsection{Do a Good Job in the Management and Education of Talents}

In the management education of talents, it is unwise to blindly use the power of superiors to "threat" subordinates to complete tasks. When facing the management and education of talents, the leading cadres of the unit organization must "do both good and strong".

Regarding "might": First, we must establish good political rules. Paying attention to politics and observing the rules are the first tasks that must be done. This is to educate talents to be firm and establish their overall view. The second is to 
maintain good work discipline. The personal growth exercises are all carried out in their specific jobs. Loving the job, respecting the job, and observing discipline are the basis for learning experience and knowledge and improving one's own ability. The third is to keep the bottom line of the law well. As the staff of the public sector, they must know the law, understand the law, abide by the law, and use it, and strengthen the establishment of legal awareness, legal thinking and legal system concepts. The fourth is to control the direction of thinking. Cultivate the staff in the public sector to establish the correct three views, strengthen the awareness of self-protection and the ability to resist and prevent corruption.

Regarding "grace": In fact, it is the opposite of "strict management", that is, "be kind". One is to carry out different career development plans according to their individual characteristics and actual conditions, so that individuals can develop fully and appropriately to reflect their own life value. The second is to give talents enough platforms to show themselves and tap their possible resources. After discovering their shining points and outstanding performance, give them timely praise and corresponding rewards, and give them the attention they deserve. The third is to build a good environment for their growth. Only in a harmonious, friendly, and caring atmosphere can they develop positively and coordinately. Environmental atmosphere is very important for the development of talents. The fourth is to broaden their promotion channels as much as possible, so that they have more choices and more possibilities, and let them always look forward to tomorrow and not give up hope easily.

\section{Conclusion}

Based on the theory of "social man" hypothesis, fully develop human resources in the public sector. To perfect the current deficiencies, we must: strengthen the introduction and selection of talents, and do a good job of "fitting people and positions"; improve talent training and insist on achieving "all-round development"; carry out scientific management education and do a good job of "enhancing both grace and power". Only in this way can the public sector talent team meet the development needs of the current situation and the development requirements of the new era, and can better help the Chinese nation achieve great rejuvenation. The realization of the Chinese Dream is inseparable from the support of sustainable, healthy, high-quality and efficient talents. The limitation of this article is that the research on human resource development in the public sector only stays on the theoretical basis, and does not construct a detailed theoretical framework model. Secondly, there are no supporting results of data or empirical cases.

\section{Conflicts of Interest}

The authors declare no conflicts of interest regarding the publication of this paper. 


\section{References}

Chen, N. (2017). Human Nature Hypothesis and Human Resource Management. Charming China, No. 22, 29-30.

He, X. (2017). Meeting People's Growing Needs for a Better Life. People’s Forum, No. z2, 64-67.

Liu, X. (2013). Research on Management Innovation from the Perspective of "Social Man" Hypothesis Theory. Leadership Science, No. 11, 65-66.

Pan, S., \& Yang, M. (2017). Evolution of Human Resource Development Theory. Journal of Southwest University for Nationalities: Humanities and Social Sciences, No. 12, 244-247.

Shao, J., Liu, W., \& Li, K. (2013). Enlightenment of "Social Man" Hypothesis in Hawthorne Experiment on Government Employee Management. Inner Mongolia Science and Technology and Economy, No. 12, 15-16. 